\title{
Comments on "costly search and consideration sets in storable goods markets" by Tiago Pires
}

\author{
Stephan Seiler ${ }^{1}$
}

Published online: 1 September 2016

() Springer Science+Business Media New York 2016

I am honored to have been asked to provide comments on this interesting paper that makes a very nice contribution to both the literature on consumer search and the one on dynamic demand models for storable products. The paper enriches a storable good demand model such as the ones presented in Erdem et al. (2003) or Hendel and Nevo (2006) by combining it with a search model in the spirit of Stigler (1961). This is not only impressive in terms of the methodological complexity of combining two modeling devices that are hard to handle on their own, but also makes a contribution in terms of answering an interesting and novel substantive question.

The paper starts by providing some simple descriptive data patterns which show that at high inventory, i.e. shortly after a purchase, consumers are more likely to purchase their preferred brand whereas at lower inventory they are more likely to switch to a competing brand, in particular when that brand is offered at a reduced price. I have not seen this pattern documented before and find it intriguing with regards to the implications of inventory dynamics for brand choice and price sensitivity.

The author argues that imperfect information and search behavior are the driver behind the data patterns just described and hence the paper proposes an inventory model that incorporates a model of consumer search across products at every purchase occasion. While I believe that the nature of the substitution patterns observed in the data are not necessarily inconsistent with a perfect information dynamic demand model (I will return to this point in more detail below), the paper does provide a model that is able to more flexibly match the data in this regards and that does so using an internally consistent and intuitively appealing modeling device, which is the consumer search process.

Stephan Seiler

sseiler@stanford.edu

1 Stanford University, Stanford, CA, USA 
Table 1 Illustrative example: static utilities and decisions

\begin{tabular}{llll}
\hline Utility Brand A & 3 & Regular Price & 3 \\
Utility Brand B & 4 & Promotional Price & 1 \\
Promotion & Promotion & Optimal (Static) & Payoff \\
for Brand A & for Brand B & Decision & \\
0 & 0 & B & 1 \\
0 & 1 & B & 3 \\
1 & 0 & A & 2 \\
1 & 1 & B & 3 \\
\hline
\end{tabular}

To clarify my understanding of the contribution of the paper, I provide a very simple toy model that I believe captures the key elements affecting brand choice as a function of inventory. My example is based on a dynamic demand model with inventory holdings which does not incorporate search. I highlight what such a model entails for brand choice patterns as a function of inventory and then discuss how the search process proposed in this paper allows the researcher to better match the data.

Assume there are two brands $j \in\{A, B\}$ and the consumer prefers brand $\mathrm{B}$ at identical prices. Both brands independently go on promotion 50 percent of the time and are otherwise offered at their identical regular price. Consumer utility from purchasing brand $j$ is equal to a brand preference parameter minus price: $u_{j}=\delta_{j}-p_{j}$. Table 1 illustrates the payoffs and optimal decisions in a static setting for particular values of the brand preference parameters as well as regular and promotional price levels. These values are chosen in a way that the consumer might buy the less preferred product A, but only if product A is promoted and product B is not. This happens 25 percent of the time. In 75 percent of cases the preferred brand $B$ is purchased.

Now assume that there are two time periods and the consumer does not know prices in the second period (but he knows their distribution) when making a purchase decision in the first stage. The consumer can only buy in one time period, but he has to buy in the second period at the latest. This captures inventory dynamics in a very simple way, the forced purchase in the second period can be thought of as a high disutility from stocking out. ${ }^{1}$ When deciding whether to purchase in the first period, the consumer will compare first period utility with the expected utility of waiting. The latter is equal to a simple average of the payoffs presented in the right-most column of Table 1 , in this case 2.25 . Therefore, the consumer will only purchase in the first period if his preferred brand is promoted, otherwise he will not make a purchase and wait until the second period.

Three results emerge from this simple model. The first finding is a standard feature of inventory models, the probability of making a purchase increases as inventory decreases. It is equal to $100 \%$ in the second period but only $50 \%$ in the first period.

\footnotetext{
${ }^{1}$ For simplicity the example ignores discounting and inventory costs. Introducing those elements does not change the main intuition regarding brand choice as a function of inventory.
} 
The other two findings have not been emphasized prior to this paper and they concern brand purchase shares as well as differential price responsiveness across brands. While the probability of making a purchase is lower in the first period, the probability of purchasing brand $\mathrm{B}$ (conditional on making any purchase) is higher. The conditional purchase share for product B is $100 \%$ in the first period and decreases to $75 \%$ percent in the second period. Furthermore, brand B is only purchased in period one if it is on promotion. Intuitively, when the consumer still has inventory left and does not need to purchase (in the first period), the option value of waiting and potentially encountering his preferred brand on promotion in a later time period outweighs the benefit for purchasing the less preferred brand earlier (even when it is promoted).

The paper provides empirical support for the latter two patterns in a simple descriptive way as I described above. Just to re-iterate, the author shows that consumers are more likely to purchase their preferred brand (here identified as the brand that was most frequently purchased in the past) when inventory is high and such purchases predominantly happen when the preferred brand is on promotion.

So how does search behavior factor into this process? In my mind, the general patterns described above can arise even without imperfect information and consumer search. However, the type of changes in brand choice patterns as a function of inventory that the toy model illustrates were "baked into" standard inventory models without there being a parameter that particularly caters to matching that dimension of the data. Most typically, demand models for storable goods heuristically think of quantity choice and purchase frequency as providing variation to identify storage cost parameters and brand choice as identifying brand preferences and the price coefficient. ${ }^{2}$ Hence, changes in brand choice patterns as a function of inventory play no particular role in identifying a specific parameter in these models. Incorporating search across products provides an elegant and intuitively appealing way of rationalizing how brand choice changes with inventory.

The way this works in the model is that when introducing search costs, the reaction of brand choice patterns to inventory changes becomes more pronounced relative to the perfect information case. To see why this happens, consider the case where the consumer is perfectly informed about prices and finds it optimal to purchase his second favorite brand when it is promoted and inventory is 3 days away from depletion (earlier than 3 days he only purchases his most preferred brand when it is promoted). In a model where the consumer has to incur a search cost in order to find out the price of each product, he might optimally decide not to search his second favorite product at the same inventory level and hence the preponderance of preferred brand purchases at 3 days from inventory depletion will be higher than in a perfect information scenario. As we increase the search cost, the purchase share of the preferred brand will increase more strongly in inventory and hence the brand choice / inventory relationship in the data will inform the magnitude of the per-product search cost parameter.

\footnotetext{
${ }^{2}$ In Hendel and Nevo (2006), the separation of parameters that are identified by brand choice and those that are identified by dynamic purchase patterns is particularly clear.
} 
While I find the novel data patterns described in this paper interesting and the modeling device used to rationalize them appealing, I do have few smaller quibbles along two dimensions. First, the paper present an ambitious attempt at combining two modeling paradigms that are complicated enough on their own and hence some of the modeling choices made for reasons of tractability, do feel a little restrictive at times. Second, the paper could have been pushed further into developing the substantive insights that follow from this new model and that other (simpler) inventory models would not have been able to capture. In both respects, future research might be able to develop things further building upon on the basic framework in this paper. In terms of the modeling assumptions, my main concern arises from the fact that the model is restrictive in the way preference heterogeneity is incorporated. Because the identity of each consumer's preferred brand plays a key role in how brand choice is affected by inventory, this is the dimension along which it would be most desirable to allow for more flexibility.

In terms of substantive insights, the modeling framework holds great promise for informing important questions in marketing and economics. To give just one example, the change in brand choice patterns and price sensitivity as a function of inventory has implications for the optimal timing of promotions because shortly after a purchase, consumers will search very little and hence promotions will be ineffective. Furthermore, niche brands that are generally searched less frequently might differ in their optimal promotional frequency relative to more established brands. My broad take-away in this regard is that the strength of the paper lies in modeling carefully how substitution between brands evolves over time as a function of inventory. Therefore, any type of analysis that focuses on how to optimally allocate marketing activity over time in a competitive environment could use this framework as a starting point.

\section{References}

Erdem, T., Imai, S., \& Keane, M.P. (2003). Brand and quantity choice dynamics under price uncertainty. Quantitative Marketing and Economics, 1, 5-64.

Hendel, I., \& Nevo, A. (2006). Measuring the implications of sales and consumer inventory behavior. Econometrica, 74(6), 1637-1673.

Stigler, G.J. (1961). The economics of information. Journal of Political Economy, 69(3), 213-225. 